\title{
С.Г. Нуралиева
}

Азербайджанский университет языков, Азербайджан, г. Баку e-mail: sabina.bagiyeva.sb@gmail.com

\section{ПРАГМАТИЧЕСКАЯ НАПРАВАЕННОСТЬ ОЦЕНКИ В ПОАИТИЧЕСКОМ АИСКУРСЕ}

\begin{abstract}
В статье рассматривается категория оценки с точки зрения ее прагматической направленности в политическом дискурсе. Цель данного исследования - проанализировать особенности функционирования оценочной семантики в политическом дискурсе. На основе проведенного анализа оценка представляется как одна из главных деталей политического дискурса. Оценка является категорией, которая основывается не на реальных характеристиках преАметов и явлений, а на основе субъективных впечатлений и эмоциональных реакций на них. Передавая субъективную форму речи, она воздействует на получателя и выражает в основном не семантический, а прагматический аспект речевой ситуации. Аискурсивность оценки показывает ее неразрывную связь с прагматической функцией языка. Следовательно, оценка должна влиять на аАресата, выражая в основном не семантический, а прагматический аспект ситуации общения. Прагматическая направленность оценки позволяет политическим деятелям выражать свое отношение к окружающей действительности, выделять определенные части текста, а также привлекать и манипулировать публикой. Политический Аискурс субъективно отражает мир, так как адресант производит речь в силу ее оценочного свойства. В связи с этим субъект политического дискурса, отражающий некоторые интересы и имеющий определенные цели и задачи, передает действительность в тексте, что способствует манипулированию информацией в желаемом Аля получателя направлении. Политическая речь является ритуальной формой преАставления обществу политических целей в соответствии с основной целью политики получение и сохранение власти. В политическом Аискурсе характер оценки - биполярный (правильный - неправильный), соотносится с системой идентификации: «мы / своя группа положительно» - «они / чужая группа - отрицательно». Основание же оценки преследуют одну цель - борьба за власть: ее получение, хранение, осуществление, стабилизация и перераспределение. Борьба за власть имеет Ава аспекта: борьбу политиков, находящихся во власти, при сохранении своего положения и борьба политиков, которые илут к власти. Оценка выражает сущность политического Аискурса, его форму, выбор языковых среАств, эффективность, Аейственность и отношения межАу говорящим и реципиентом.
\end{abstract}

Ключевые слова: политическая коммуникация, оценочная лексика, прагматический аспект, речевая ситуация, антропоцентрическая категория, оппонент.

$$
\begin{gathered}
\text { S.G. Nuraliyeva } \\
\begin{array}{c}
\text { Azerbaijan University of Languages, Azerbaijan, Baku } \\
\text { e-mail: sabina.bagiyeva.sb@gmail.com }
\end{array}
\end{gathered}
$$

\section{The pragmatic orientation of the evaluation in political discourse}

The article deals with the pragmatic orientation of the evaluation in political discourse. The aim of the research is to analyze the features of the functioning of evaluative semantics in political discourse. This analysis presents evaluation as one of the main details of political discourse. Evaluation is a category that is based not on the real characteristics of objects and phenomena, but on the basis of subjective impressions and emotional reactions to them. Transferring the subjective form of speech, it influences the addressee and expresses mainly not the semantic, but the pragmatic aspect of the communicative situation. The discursiveness of evaluation shows its inextricable connection with the pragmatic function of language. Therefore, the evaluation should influence the addressee, expressing mainly not the semantic, but the pragmatic aspect of the communicative situation. The pragmatic orientation of the evaluation allows politicians to express their attitude to the surrounding reality, highlight certain parts of the text, and also attract and manipulate the public. Political discourse subjectively reflects the world, since the addressee makes speech due to its evaluative properties. In this regard, the subject of political discourse, reflecting certain interests and having certain goals and objectives, conveys reality in the text, which contributes to the manipulation of information in the direction desired by the recipient. Political speech is a ritual form of presenting political goals to society in accordance with the main goal of poli- 
tics, i.e obtaining and maintaining power. In political discourse, the nature of the evaluation is bipolar (correct - incorrect), correlates with the identification system: "we / our group - positively" - "they / alien group - negatively". The basis of the evaluation pursues one goal, i.e. power struggle: its receipt, storage, implementation, stabilization and redistribution. The struggle for power has two aspects: the struggle of politicians in power, while maintaining their position, and the struggle of politicians who go to power. Evaluation determines the content of political discourse, its form, choice of linguistic means, efficiency, effectiveness and the relationship between speaker and recipient.

Key words: political speech, pragmatic aspect, communicative situation, evaluative vocabulary, anthropocentric category, opponent.

\author{
С.Г. Нуралиева \\ Әзірбайжан тілдер университеті, Әзірбайжан, Баку к. \\ e-mail: sabina.bagiyeva.sb@gmail.com
}

\title{
Бағалаудың саяси дискурстағы прагматикалық бағыты
}

Мақалада бағалау категориясы саяси дискурстағы прагматикалық бағыты тұрғысынан қаралады. Саяси Аискурстағы бағалау семантикасының жұмсалу ерекшеліктерін талдау мақаланың негізгі мақсаты болып табылады. Осы та^дау негізінде бағалау саяси дискурстың негізгі тетіктерінің бірі ретінде беріледі. Бағалау - заттар мен құбылыстардың шынайы сипатына емес, оларға деген субъективті әсер мен эмоционалды реакцияларға негізделетін санат. Сөйлеудің субъективті формасын беру арқылы қабылдаушыға ықпал ете отырып, негізінен сөйлеу жағдаятының семантикалық емес прагматикасын білдіруге қызмет етеді. Бағалаудың Аикурсивтігі оның тілдің прагматикалық қызметімен тығыз байланысының айғағы. Яғни бағалау сөйлесу жағлаятының семантикалық мәні емес прагматикалық мәнін білдіре отырып аАресатқа ықпал етуі. Бағалаудың прагматикалық бағыты саяси тұлғалардың айналасына өзінің көзқарасын білдіруге, мәтіннің белгілі бөліктерін айрықшалауға, сонымен қатар шаршы топты үндеуге және басқаруға септігін тигізеді. Саяси дискурс субъективті түрде әлемнің бейнесі тәріздес, себебі адресанттың сөз саптауы оның бағалау қасиетінің әлеуетіне байланысты болып келеді. Осыған орай белгілі бір мақсат пен міндетті көздеуші саяси дикурс субъектісі мәтінде ақиқатты беруге тырысады, ал ол ақпаратты өз қажетіне жаратуға ықпал етеАі. Саяси сөз саясаттың негізгі мақсатына - билікке қол жеткізу мен оны сақтап қалуға - сәйкес субъектінің қоғамға саяси мақсатын білдірудің рәсімі болып табылады. Сонымен қатар аталған дискурс түрінде бағалау сипаты биполярлы (Аұрыс - бұрыс) («біз/өз тобымыз - жағымАы» - «олар/ өзге топ - жағымсыз») топтастыру жүйесіне сәйкес. Бағалау негізі бір ғана мүлдені көздейді, ол мүдле - билікке талас: оған қол жеткізу, оны сақтап қалу, жүзеге асыру, тұрақтандыру және бөлу. Билікке талас биліктегі саясаткерлердің өз орнын сақтап қалудағы күресін және билікке таласушы саясаткерлердің күресін қамтитын екі аспектіден тұрады. Бағалау саяси дискурстың мәнін, оның формасын, тіл құралдарын таңдауын, тиімділігін, сөйлеуші мен реципиенттің арасындағы қатынас пен ісәрекетті білдіреді.

Түйін сөздер: саяси қатысым, бағалау мексикасы, прагматикалық аспект, сөйлеу жағдаяты, антропоөзекті санат, оппонент.

\section{Введение}

В последние годы политический дискурс изучается с разных точек зрения и с использованием разных методов анализа. Междисциплинарная лингвокультурологическая методология исследования позволяет рассматривать политический дискурс как интерсубъективную и интерактивную вербальную коммуникацию, осуществляемую посредством текста, коммуникативная цель которой - борьба за политическую власть путем манипулирования или контроля общественного мнения. В теории дискурсивного анализа термин интерактивность подразумевает соучастие и сотрудничество коммуникантов в вербальном дискурсе, в то время как интерсубъективность понимается как их единство, переживаемое психологически и феноменологически. Соответственно, ученые сосредотачиваются на изучении прагматической стороны политического дискурса, поскольку прагматика имеет дело с конкретными ситуациями, в которых участвуют конкретные коммуниканты со своими конкретными намерениями и психоэмоциональными диспозициями.

Работа актуальна тем, что в ней изучены способы выражения прагматической направленности оценки в специфических характеристиках политического дискурса, что до настоящего времени не было предметом специальных исследований. 


\section{Обзор литературы}

Потребность политического дискурса в оценочном словаре является неизменно высокой, хотя бы потому, что высказывания политиков очень часто характеризуются остротой суждений относительно их политических оппонентов. Оценка может быть определена как объективное или субъективное отношение говорящего к определенному объекту, который может быть явно или неявно выражен языковыми средствами. В истории лингвистических исследований существует множество определений оценки. Из них мы рассмотрим лишь некоторые.

В «Словаре лингвистических терминов» понятие «оценка» описывается как взгляд сообщающего, его взаимосвязь - согласие либо несогласие, желание, поощрение и т.д. - как одна из главных частей стилистического смысла (Ахманова, 1969: 305).

М.Р. Желтухина определяет оценку как «акт человеческого сознания, заключаюшегося в сравнении предметов, сопоставлении их свойств, определении роли в жсизни субъекта и его последствий, которые сохраняются в сознании и языке в положительной, отрицательной и нейтральной формах» (Желтухина, 2003: 223).

Оценка, наблюдаемая во всех сферах жизни человека, носит универсальный лингвистический характер. Она считается семантической и прагматической категорией и может быть одним из самых мощных средств воздействия на аудиторию. Это позволяет изучать оценку как комплекс ее языковых и коммуникативных особенностей, как семантическую и прагматическую категорию. Значение языкового знака и в семантике, и в прагматике трактуется по-разному. Если семантика отвечает на вопрос «Что означает?», то прагматика ставит вопрос «Что вы хотите сказать, употребив данное слово?» (Leech, 1983: 5-6).

Оценка - это категория, предопределенная субъективной сегментацией мира, основанной не на реальных характеристиках предметов и явлений, но только на основе субъективных впечатлений и эмоциональных реакций на них (Арутюнова, 1988: 43). Согласно Л.Ю. Иванову, оценка передает субъективную форму речи (Иванов, 2003: 312). Таким образом, оценка призвана оказать влияние на адресата, выражая в основном не семантическую, а прагматическую сторону коммуникации.

Н.Е. Кузнецова и Е.В. Шевченко акцентируют свое внимание на прагматической направлен- ности оценки: «оченка - прочесс и итог определения субъектом меры значимости объекта с учетом возможности последнего удовлетворять конкретные нужды и интересы субъекта, другими словами определения прагматической важности объекта» (Кузнецова, 2004: 71).

Согласно определению Томпсона и Ханстона оценка - это широкий термин для выражения отношения или позиции говорящего или писателя, точки зрения или чувств по поводу сущностей или предложений, о которых он или она говорит. Такое отношение может относиться к определенности, обязательству, желательности или любому из ряда других наборов ценностей (Thompson and Hunston, 2000: 5).

Основными элементами структуры оценки выступают ее субъект и объект. Согласно Е.M. Вольф структура оценки придерживается определенной формулы «А г В», где «А» исполняет субъект оценки, «В» - ее объект, а «г» - оценочное отношение, которое имеет значения «хорошо / плохо». Оценочный предикат «г» характеризуется рядом признаков, выражающих своеобразие оценочной связи между субъектом и объектом. Этими признаками являются эмотивность, оценочность (отношение по признаку «хорошо / плохо»), эмоциональность / рациональность и эффективность (Вольф, 2002: 12).

В политическом дискурсе основными элементами структуры оценки являются политические деятели. Это - политик, президент, лидер политической силы, государственный деятель и т.д. (адресант) и социум (адресат). Однако традиционная модель коммуникации «говорящий - слухач» (адресант - адресат) в политическом дискурсе превращается в более глубокую, двухмерную: политик - оппонент - общество. Политик имеет дело с этими двумя адресатами; к тому же общество в этой иерархии имеет первое место и положительную оценку. В этом случае оппонент является «принужденным» адресатом; расположение к нему даже если не негативное, то хотя бы критическое, ибо оппонент является соперником политика-говорящего в борьбе за главного адресата - общество.

\section{Результаты и обсуждение}

Политический дискурс рассматривается как вид политического поведения и часть политического процесса в политике (Van Dijk, 1997: 14). Во время избирательных кампаний в этот процесс вовлекаются все члены общества, и это приводит к их идеологической поляризации. В этом 
случае категория оценки требует особого внимания и дальнейшого анализа. С помощью оценки можно выделить определенные части текста, и таким образом, привлечь внимание аудитории и манипулировать ею. Это также помогает речи ораторов звучать более убедительно, уверенно и мощно.

Оценку можно назвать онтологической свойством языковой личности. Оценочное представление об окружающем мире трактуется как такое, что ставит в центр концептуальной картины мира субъективное расположение говорящего к реальности. Субъективное ценностное отношение говорящего опирается на объективные свойства оцениваемого и выражается объективными языковыми средствами. Лексическая сфеpa, взаимодействуя с синтаксической, отражает различные цели оценивания в коммуникативных тактах: одобрение - похвала - захват / неодобрения - осуждение - возмущение; области оценки (предметную, личную, событийную, фактическую и т.д.), объекты оценки, формы оценивания.

Хотя в нынешнее время имеется большое количество конкурирующих взглядов на субъективность, в широком смысле, она определяется как связанная с самовыражением, то есть выражением установок, убеждений, чувств, эмоций, суждений, воли, личности говорящего и т. д. (Lyons, 1982: 110). Исследования субъективности обычно касаются трех аспектов языка: 1) точка зрения говорящего как формирующая языковое выражение; 2) выражение аффекта говорящего по отношению к предложениям, содержащимся в высказываниях; 3) выражение говорящим модальности или эпистемического статуса предложений, содержащихся в высказываниях (Finegan, 1995: 4). Итак, сфера реализации политического дискурса - это диалог между политиками / управленцами и избирателями по поводу получения и удержания политической власти, который имеет преимущественно опосредованный и театрализованный характер. Основными концептами дискурса выступают политик и власть.

Мы определяем оценку либо как положительную, либо как отрицательную. Согласно оценочности, противопоставление слов «хорошо - плохо» имеет различные значения в сознании репрезентантов конкретных общественных групп.

В рамках оценочности градация включает в себя множество средств интенсификации, которые можно разделить на созданные силой или фокусом. Общий пример оцениваемого суждения таков: достаточно хорошо - неплохо - очень хорошо - чрезвычайно хорошо (Martin \& White, 2005: 136). Принимая во внимание результаты психолингвистических исследований, Вольф выделяет в шкале следующие элементы: очень хорошо - хорошо - достаточно хорошо - удовлетворительно - достаточно плохо - плохо - очень плохо (Вольф, 2002: 52). Очевидно, что оценочные элементы, используемые для описания политика и его / ее партии, будут иметь тенденцию к увеличению, в то время как отрицательные оценочные элементы с уменьшением масштаба обычно выбираются для оппонентов.

Оценка тоже по своей природе антропоцентрична. Это означает, что содержание оценки отражает человеческую природу и зависит от ценностей и аксиологических норм человека. Поскольку оценка - антропоцентрическая категория, она зависит от системы общих ценностей определенного языка сообщества и во многом предопределена национальной спецификой восприятия мира участниками данного сообщества. Оценка - это категория, касающаяся человека и всего, того что так или иначе связано с ним / ней, и это влияет на физическую, ментальную и социальную сущность человека. Оценка представляет человека как цель, к которой обращен весь мир. Политический дискурс - явление антропоцентрическое, он субъективно отражает мир, так как адресант «назначает» речь в силу ее оценочного свойства. В связи с этим предмет политического дискурса определяет реальность в самом тексте, при этом отражая некоторые интересы и имея определенные намерения и назначения. Данный тип дискурса различается субъективностью, что облегчает манипулирование сообщением в желаемом для адресата направлении.

К системообразующим характеристикам оценочности политического дискурса можно отнести: 1) наличие массовой аудитории; 2) господство явления эмоциональности и большой ценности неинформационного общения; 3) значимая неопределенность, которая связанна с воображаемостью ряда денотатов и иррациональностью; 4) применение приемных действий, во главе с эвфемизацией, осознанным отступлением, намеками и сносками на слухи; 5) опосредованность политического общения явлением массмедии; 6) публичность, важность «работать на зрителей», притягивая их своим имиджем; 7) энергичность стиля политического языка, которая обусловленна остротой передаваемой действительности и непостоянностью политического состояния. 
Оценка показывает «контекстно-зависимую многозначную функциональность», и, следовательно, в ее анализ должен быть включен более широкий контекст. Оценка - очень сложное текстовое явление, как отмечают многие исследователи: когда мы рассматриваем значения расширенных, связанных текстов, которые не заключены в отдельные предложения, мы часто сталкиваемся с языковыми явлениями, которые открывают новые семантические ресурсы на уровне текста. Это особенно верно в отношении семантики оценки из-за ее тенденции к «просодическим» реализациям, то есть реализациям, которые имеют тенденцию распределяться через предложение и через границы предложений.

Это говорит о том, что феномен оценки можно правильно понять, интерпретировать и проанализировать только в его контексте. С одной стороны, языковые средства выражения оценки сильно зависят от контекста; с другой стороны, анализ дискурсивной семантики оценки показывает, как оценка распространяется как волна по тексту и придает ему особую «оценочную просодию» (Hunston, 1994: 200). Мартин решительно заявляет об этом: «мы никогда не поймем функцию оценки в культуре, если наши исследования будут основаны, пусть и в количественном отношении, на анализе «декотекстуализированных» примеров» (Martin, 2005: 177). Таким образом, оценочная сила лингвистических выражений может быть незаметна при автоматическом корпусном исследовании (Stotesbury, 2003: 331). Более того, такой анализ выявит не только примеры оценки говорящего, но и случаи, когда оценка просто цитируется.

В политическом дискурсе категория оценки выступает в двух формах: рационально и эмоционально. В свою очередь эти типы категории оценки могут выражаться как эксплицитно (адресант выражает свою точку зрения прямо) и имплицитно (адресант выражает свою точку зрения косвенно). Вопрос о том, какой фактор в оценке первичен - эмоциональный или рациональный, является одним из наиболее спорных в аксиологии, и в большинстве случаев является решающим для оппозиций субъектного и объектного в концепции оценки. Эмоциональная оценка - прямой ответ на объект (явление, предмет), выраженная возгласом, аффективными словами, словами образами. Эмоциональная оценка бывает выразительной. В то время как рациональная оценка подразумевает оценочный взгляд и методы выражения, которые принимают во внимание этот тип оценки. Экспрессивность не свойствен- на для рациональной оценки. Рациональность оценки усиливается с помощью аффективных прилагательных.

Эмоциональность (либо экспрессивность) образуется за счет многочисленных сочетаний синтаксических компонентов, добавляющих речи не только целостность и последовательность, но и дополнительное выражение. Эмоциональное отношение (состояние) может стать предметом отражения в языке и, следовательно, быть осознаваемым членами языкового коллектива.

По мнению австрийского ученого Рут Водак, политический язык, кажется, существует между двумя полюсами. С одной стороны, он представляет собой особый, функционально определенный язык, тогда как, с другой стороны, его можно рассматривать как политический жаргон идеологически сплоченных групп людей (Wodak, 1989: 138).

Задача при построении политического общения состоит не в том, чтобы объективно описать реальность, а в том, чтобы подчеркнуть определенные особенности этого феномена, убедив получателя, побудив его к определенным действиям, желательным для создателя дискурса в определенных обстоятельствах. Данный процесс формируется в определенном обществе до политического события. Для этого в политическом дискурсе говорящий может использовать аксиологический (оценочный) словарь, являющийся неким центром тяжести, который привлекает внимание и влияет на сознание читателя.

Оценка будучи одной из форм модальностей, накладывается на описательную сущность языкового выражения (Вольф, 2002: 164). Свойства модальности тесно связаны с прагматическими аспектами - системой правил, определяющих, как язык используется и трактуется в контексте. Согласно точке зрения, принятой в зарубежной лингвистике, прагматика - это отношение языкового элемента к его создателям, потребителям и реципиентам, вовлеченным в коммуникативную ситуацию. К выполняемым функциям в контексте этого отношения относятся: функция сообщения, которая подразумевает информирование получателей с помощью текстов; функция подсказки, подразумевающая апелляции к оценке или определенному поведению; функция оценки, подразумевающая оценку отправителя; справочная функция. Лингвистическая модальность возникает как производная от всех них. Важно соотнести модальности, присущие политическим языкам, с принципами логики модально- 
сти, то есть анализом суждений, которые имеют отношение к конкретному определению связей, с их оценкой. Такие модальные операторы, как «необходимо», «возможно», «условно», «знает», «предполагает», «было», «будет», «незаменимый» и др. можно разделить на абсолютные (применимые к отдельным объектам и их свойствам) и относительные (относятся к парам объектов и отношениям между ними).

Политический дискурс определяется полилогическим типом коммуникации, т.е. особенным многогранным опосредованным типом речевой коммуникации, конструктивно-композиционным обращением к нескольким собеседникам и полифонией разных авторов.

Прагматическая направленность оценки также выражается в следующих особенных чертах политического дискурса: 1) агрессивность; 2) агонистическая способность; 3) полемичность; 4) идеологический характер.

1) Агрессивность. Агрессия - это главный элемент политической речи. Агрессия в политической коммуникации близко взаимосвязана с понятиями власти и иерархии. Слово «иерархия» происходит от греческих слов и означает отношения подчинения, цепочка команд, цепочка команд от низших к высшим, а «власть» восходит к латинскому dominantis, выражающий «преобладание, рвение к руководству, распространенности и лидерству» (Кузнецов, 2000: 376).

Существуют конкретные речевые акты представляющие вербальную агрессию. Данные акты являются проявлением политической силы и сконцентрированы на убавление положения адресата. Выделяются следующие речевые акты изгнания, требования и заявления, осуждения и угрозы.

Функция агрессивных высказываний в политическом дискурсе заключается «в устремленности на опровержение противника, снижение его политического состояния» (Шейгал, 2004: 121).

2) Агонистическое умение, т.е. конкурентоспособность. При рассмотрении политического дискурса как борьбы за господство приводит выделению следующего параметра - агональности. Как отмечает Н.В.Кондратенко, что агональность указывает на наличие в политическом контексте «элементов соперничества, понимание политики как разновидности соревнования: кто первый? Агональность предполагает не просто участие в игре, а обязательную победу» (Кондратенко, 2007: 49), т.е. в этом случае важен не процесс игры, а результат, как в спортивных играх. Не- прерывное состязание между властной партией и оппозицией образует фундамент политического дискурса.

3) Полемичность и театральность. Полемичность и театральность направлены на манипулирование общественным мнением двумя основными целями: либо завоевать поддержку людей, либо спровоцировать их негативное отношение и эмоции против политических противников. Этим объясняется ситуация, когда речь политика ценится его / ее сторонниками и получает отрицательную оценку со стороны своих оппонентов. Данная категория соединяет политический дискурс со сценическими и маркетинговыми дискурсами. Полемичность политических общений связана с тем, что народ, являясь одной из сторон коммуникации, выполняет функцию не безусловного адресата, а адресата-зрителя, который принимает нынешние политические действия как конкретную игру, сыгранную для них с занимающим сюжетом и непредвиденным заключением.

4) Идеологический характер. Идеологический характер основан на коллективных ценностях, нормах и интересах. Это свойство позволяет сравнивать политический и военный дискурсы. Война представляет собой продолжение политики иными средствами. Война и политика взаимодействуют в тех областях, которые обеспечивают убеждения и ход войны с точки борющихся сторон.

На основе проведенного исследования мы приходим к следующим результатам: 1) анализ особенностей функционирования оценочной семантики в политическом дискурсе предоставляет возможность обнаружить универсальное и национальное своеобразие границ семантического пространства индивида; 2) используя оценку, говорящий высказывает свое личное отношение к конкретному виду информации; 3) оценка тесно связана с прагматической стороной языка; 4) оценка задает содержательную настроенность политического дискурса, его форму, подбор языковых средств, результативность, эффективность и отношения между говорящим и получателем.

\section{Выводы}

Таким образом, оценка как главная деталь политического дискурса помогает политическим деятелям вербально высказать свое отношение к находящейся вокруг реальности, мониторингам на будущее и перспективам конфигурации обста- 
новки во всем мире на основании своей иерархии и системы ценностей. Оценка являет собой философскую, логическую, психологическую, лингвистическую категорию, уникальность ко- торой не только отражает суть ценности объекта для субъекта, но также в некотором роде влияет на реципиента, который меняет свое ментальное пространство, формируя мировоззрение.

\section{Литература}

Ахманова О.С. Словарь лингвистических терминов. - М.: Сов. энциклопедия, 1969. - 607 с.

Желтухина М.Р. Тропологическая суггестивность масс-медиального дискурса: о проблеме речевого воздействия тропов в языке СМИ: монография. - М./Волгоград: ВФ МУПК, 2003. - 656 с.

Leech G.N. Principles of Pragmatics. - N.Y.: Longman, 1983. - 250 p.

Арутюнова Н.Д. Типы языковых значений: оценка, событие, факт. - М.: Наука, 1988. - 341 с.

Иванов Л.Ю. Текст научной дискуссии: Дейксис и оценка. - М.: НИП «2Р», 2003. - 208 с.

Кузнецова Н.Е. К вопросу о некоторых способах выражения оценки. - Курган: Язык. Текст. Стиль: сб. науч. тр. - 2004. - C. $71-79$.

Thompson G., Hunston S. Evaluation in Text: Authorial Stance and the Construction of Discourse. - Oxford: Oxford University Press, 2000. $-240 \mathrm{p}$

Вольф Е.М. Функциональная семантика оценки. - М.: Едиториал УРСС, 2002. - 280 с.

Van Dijk T.A. What is Political Discourse Analysis? - Amsterdam: Belgian Journal of Linguistics. - 1997. - 11(1). - P. 11-52.

Lyons J. Deixis and subjectivity: loquor, ergo sum? - Chichester, NY: Wiley: Speech, Place, and Action. Studies in Deixis and Related Topics, 1982. - P. 101-124.

Finegan E. Subjectivity and subjectivisation: an introduction. - Cambridge: Open Journal of Modern Linguistics. - 1995. Vol. 4. - №3. - P. 1-15.

Martin J. R., White P.R. The Language of Evaluation. Appraisal in English. - New York: Palgrave Macmillan, 2005. - 278 p.

Hunston S. Evaluation and Organization in a Sample of Written Academic Discourse. - London: Routledge: Advances in Written Text Analysis. - 1994. - №4. - P. 191-218.

Stotesbury H. Evaluation in research article abstracts in the narrative and hard sciences. - Amsterdam: Journal of English for Academic Purposes. - 2003. - №2. - P. 327-341.

Wodak R. Language, Power and Ideology: Studies in Political Discourse. - Amsterdam/Philadelphia: John Benjamins, 1989. $-299 \mathrm{p}$.

Кузнецов С.А. Большой толковый словарь русского языка. - СПб.: «Норинт», 2000. - 1536 с.

Шейгал Е.И. Семиотика политического дискурса. - Москва: ИТДГК «Гнозис», 2004. - 326 с.

Кондратенко Н.В. Український політичний дискурс: текстуалізація реальності: [монографія]. - Одеса: Чорномор'я, 2007. $-156 \mathrm{c}$.

\section{References}

Akhmanova O.S. (1969). Slovar' lingvisticheskikh terminov [Dictionary of linguistic terms]. M. : Sov. Entsiklopediya, 607 p. [In Russian]

Arutjunova N.D. (1988). Tipy jazykovykh znachenij: otsenka, sobytije, fakt [Types of language values: evaluation, event, fact]. Moskva: Nauka, 341 p. [In Russian]

Finegan E. (1995). Subjectivity and subjectivisation: an introduction. Cambridge: Open Journal of Modern Linguistics, Vol.4, №3, p. 1-15. [In English]

Hunston S. (1994). Evaluation and Organization in a Sample of Written Academic Discourse. London: Routledge: Advances in Written Text Analysis, №4, p. 191-218. [In English]

Ivanov L.Yu. (2003). Tekst nauchnoj diskussii: Dejksis i otsenka [Text of the Scientific Discussion: Deixis and Evaluation]. M.: NIP «2R», 208 p. [In Russian]

Kondratenko N.V. (2007). Ukraïns'kiy polítichniy diskurs: tekstualízatsíya real'ností [Ukrainian political discourse: textualization of reality]: monograph. Odesa: Chornomor'ya, 156 p. [In Russian]

Kuznetsova N.Ye. (2004). K voprosu o nekotorykh sposobakh vyrazheniya otsenki [On the question of some ways of expressing evaluation]. Kurgan: Yazyk. Tekst. Stil’: sb. nauch. tr., pp. 71-79. [In Russian]

Kuznetsov S.A. (2000). Bol'shoj tolkovyj slovar' russkogo yazyka [Great Dictionary of Russian language]. SPb.: «Norint», $1536 \mathrm{p}$

Leech G.N. (1983). Principles of Pragmatics. N.Y.: Longman, 250 p. [In English]

Lyons J. (1982). Deixis and subjectivity: loquor, ergo sum? Chichester, NY: Wiley: Speech, Place, and Action. Studies in Deixis and Related Topics, p. 101-124. [In English]

Martin J. R., White P.R. (2005). The Language of Evaluation. Appraisal in English. New York: Palgrave Macmillan, 278 p. [In English] 
Shejgal Ye.I. (2004). Semiotika politicheskogo diskursa [Semiotics of Political Discourse]. Moskva: ITDGK «Gnozis», 326 p. [In Russian]

Stotesbury H. (2003). Evaluation in research article abstracts in the narrative and hard sciences. Amsterdam: Journal of English for Academic Purposes, №2, p. 327-341. [In English]

Thompson G., Hunston S. (2000). Evaluation in Text: Authorial Stance and the Construction of Discourse. Oxford: Oxford University Press, 240 p. [In English]

Van Dijk T.A. (1997). What is Political Discourse Analysis? Amsterdam: Belgian Journal of Linguistics, 11(1), p. 11-52. [In English]

Vol'f Ye.M. (2002). Funktsional'naja semantika otsenki [Functional semantics of evaluation]. Moskva: Editorial URSS, 280 p. [In Russian]

Wodak R. (1989). Language, Power and Ideology: Studies in Political Discourse. Amsterdam/Philadelphia: John Benjamins, 299 p. [In English]

Zheltukhina M.R. (2003). Tropologicheskaja suggestivnost' mass-medial'nogo diskursa: o probleme rechevogo vozdejstvija tropov $\mathrm{v}$ jazyke [Tropological suggestiveness of mass-media discourse: on the problem of speech influence of tropes in language]. SMI: monograph. Moskva/Volgograd: VF MUPK, 656 p. [In Russian] 